\title{
Fluvastatin increases tyrosinase synthesis induced by UVB irradiation of B16F10 melanoma cells
}

\author{
Ryszard Galus',2, Emir Sajjad1, Justyna Niderla1, Katarzyna Borowska²; \\ Krzysztof Włodarski1, Pawel Włodarski1, Jarosław Jóźwiak1 \\ ${ }^{1}$ Chair and Department of Histology and Embryology, Center for Biostructure, Medical University \\ of Warsaw, Warsaw, Poland \\ ${ }^{2}$ Department of Dermatology, Military Institute of Health, Warsaw, Poland
}

\begin{abstract}
Statins are widely used to lower plasma concentrations of lipids, e.g. cholesterol. One of the main effects of statin treatment is inhibition of hydroxymethyl glutaryl-coenzyme A reductase. The role of fluvastatin, a frequently used statin, was examined in potential modulation of tyrosinase (key enzyme of melanogenesis) synthesis. Levels of tyrosinase mRNA induced by UVB irradiation of B16F10 melanoma cell line were measured by real time PCR. Fluvastatin increases tyrosinase mRNA production induced by UVB irradiation in B16F10 melanoma cell line. Fluvastatin treatment may potentially influence melanin synthesis and protection against UV irradiation.
\end{abstract}

Key words: melanogenesis, melanoma, statins, tyrosinase

\section{Introduction}

Statins inhibit cholesterol synthesis by reducing 3-hydroxy-3-glutaryl-coenzyme A (HMG-CoA) reductase activity. It has also been shown that statins stimulate formation of substantial amounts of new bone, e.g. by increasing expression of bone morphogenetic protein-2 (BMP-2), which leads to osteoblast differentiation and bone formation [1,2]. Administration of statins may also affect heterotopic ossification [3]. BMP-2 treatment of neural crest cells increases melanogenesis by promoting the synthesis of melanin [4]. Recently, it has been demonstrated that BMP signaling plays an important role in melanocytes residing at hair follicles providing the cross-talk with the melanocortin receptor1 pathway [5]. A number of studies investigated the effects of statins on melanoma cells. Specifically, lovastatin induces apoptosis in A375 melanoma cells and also enhances response to chemotherapy drugs in the B16 mouse model of melanoma [6-9].

In numerous experiments investigating pleiotropic effects of statins, reports regarding their effect on

Correspondence: R. Galus, Chair and Department of Histology and Embryology, Center for Biostructure Research, Medical University of Warsaw, Poland, 02-004 Warsaw, Chalubinskiego Str. 5, Poland; tel.: (+48) 501834369, fax: (+4822) 6295282, e-mail: rgalus@ib.amwaw.edu.pl melanogenesis are lacking. Thus, the aim of the present work was to examine the effects of fluvastatin, a frequently used statin that effectively lowers serum cholesterol level, on melanin synthesis in melanoma B16F10 cell line.

\section{Materials and methods}

Cells. B16F10 melanoma cells were kindly donated by Dr Tomasz Stokłosa from Department of Immunology, Center for Biostructure, Medical University in Warsaw, Warsaw, Poland. B16F10 mouse melanoma cells were cultured in $75 \mathrm{~cm}^{2}$ flask and grown in DMEM+GlutaMAX medium (Gibco, NY, USA) with 10\% fetal bovine serum (Gibco, NY, USA) and $1 \%$ antibiotic/antimicotic solution (Gibco, NY, USA). Incubation was carried out at $37{ }^{\circ} \mathrm{C}$ under atmosphere of air- $\mathrm{CO}_{2}(95: 5)$.

Antibodies. Antibodies against: tyrosinase, $\beta$-actin and secondary antibodies (HRP-goat anti-rabbit or HRP-bovine anti mouse) were purchased from Santa Cruz Biotechnology (Santa Cruz, CA, USA).

Cell viability assay. All experiments were performed using cells of the same passage. After incubating B16F10 cells overnight in $25 \mathrm{~cm}^{2}$ flasks ( $5 \times 10^{4}$ cells/flask), cells were passaged to Petri dishes (Costar, Corning, NY, USA). When cells reached $40 \%$ of confluence, the medium was changed to DMEM supplemented with either $10 \%$ FCS alone or $10 \%$ FCS with fluvastatin at concentrations: $0.1 \mu \mathrm{M} ; 1 \mu \mathrm{M} ; 10 \mu \mathrm{M}$. Cell viability was determined in triplicates, using crystal violet assay $[10,11]$. After incubating B16F10 cells with test substances for up to 72 hours, culture medium was removed and the cells were stained with $0.1 \%$ crystal violet in $10 \%$ ethanol for $5 \mathrm{~min}$ at $37^{\circ} \mathrm{C}$ and rinsed four times. Crystal 


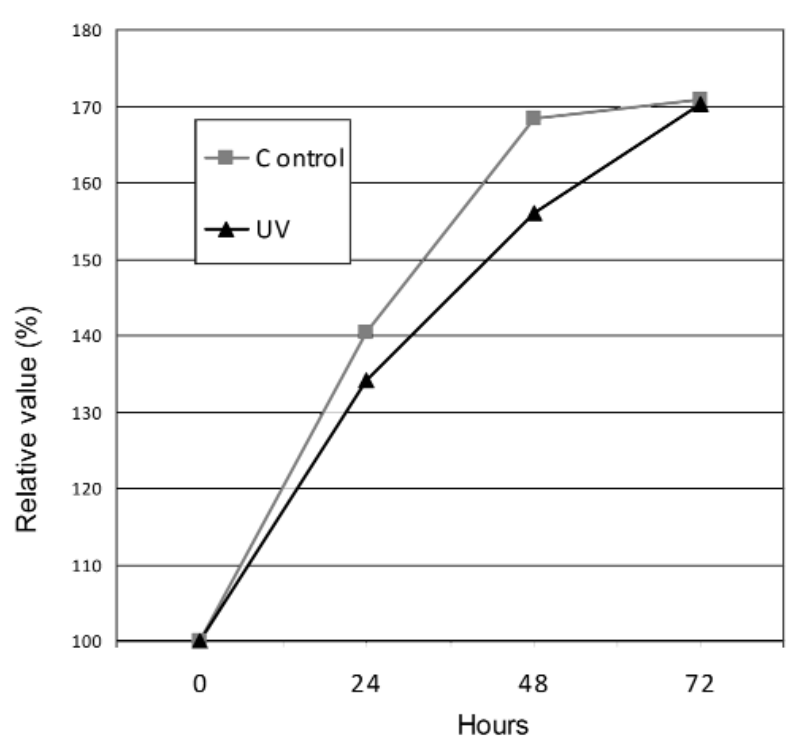

Fig. 1. Effects of UVB irradiation in B16F10 melanoma cell line at $100 \mathrm{~mJ} / \mathrm{cm}^{2}$ daily on cell viability 24,48 and 72 hours after irradiation procedure vs. non-irradiated control cells.

violet-stained adherent cells were then extracted with $95 \%$ ethanol, and absorbance was determined at $590 \mathrm{~nm}$ using ELISA reader (Tecan, Salzburg, Austria). Cell viability was also tested with UVB irradiated/non-irradiated cells.

Irradiation procedure. The source of ultraviolet was a Cosmedico stimulator (Cosmedico Medizintechnik, Schwenningen, Germany), which emits energy in the UVB range, with the peak at $311 \mathrm{~nm}$. Cells were irradiated in PBS to avoid formation of medium-derived toxic photo-products [12]. After irradiation, PBS was replaced with fresh warm growth medium with/without $1 \mu \mathrm{M}$ fluvastatin. Cells were irradiated once daily $\left(100 \mathrm{~mJ} / \mathrm{cm}^{2}\right)$ at 24,48 and 72 hours of experiment and cell viability was performed after 24 hours, following each irradiation. To examine modulation of tyrosinase mRNA, cells were irradiated once at 12 hours of experiment. In order to investigate protein content, cells were irradiated twice (at 24 and 48 hours of experiment) and the measurements were done after 24 hours following last irradiation. Non-irradiated control cells were maintained in PBS during the time of irradiation procedure.

Total RNA isolation. RNA was isolated with NucleoSpin ${ }^{\circledR}$ RNA II kit (Macherey-Nagel, Neumann-Neander D-52355 Duren, Germany), according to producer's protocol. Quality of isolated RNA was tested by electrophoresis in $1 \%$ agarose denaturing gel, containing $6 \%$ formaldehyde and buffered with MOPS (Sigma, Genosys, St. Louis MO, USA). After electrophoresis, the gel was scanned with the digital imaging system GDS9000 using GRAB-IT. 2.0 software (UVP, Cambridge, UK). Densitometric analysis of bands was performed with GelWorks software (UVP, Cambridge, UK).

Reverse transcription. RT was carried out in $20 \mu \mathrm{l}$ of a reaction mix containing $1 \times$ transcription buffer, $5.5 \mathrm{mM} \mathrm{MgCl}, 0.5 \mathrm{mM}$ of deoxynucleosides (dNTP), $2.5 \mu \mathrm{M}$ oligo dT primer, $3 \mathrm{U}$ of RNase inhibitor and $6 \mathrm{U}$ of reverse transcriptase (Reverse Transcription Kit, Promega). $1 \mu \mathrm{g}$ of total RNA was heated at $70^{\circ} \mathrm{C}$ for $10 \mathrm{~min}$, cooled to $2^{\circ} \mathrm{C}$ and added to the reaction mix. RT was performed in Eppendorf Master Cycler Gradient. Samples were incubated in $42^{\circ} \mathrm{C}$ for $2 \mathrm{~h}$ and then heated to $94^{\circ} \mathrm{C}$; cDNA was stored at $-20^{\circ} \mathrm{C}$.

RealTime PCR. Real Time PCR was performed in ABI Prism 7500 (Applied Biosystems, Warrington, UK) in 96-well optical

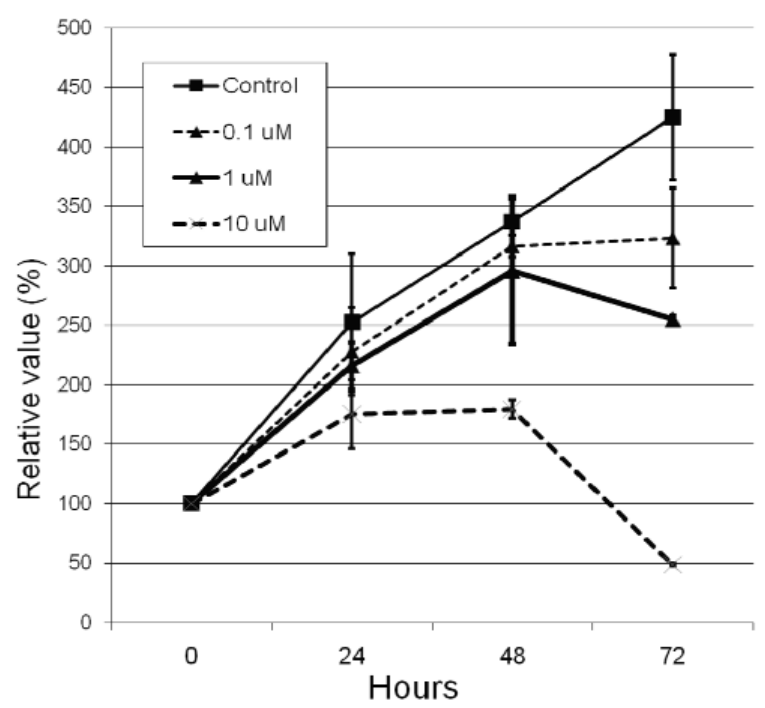

Fig. 2. Dose- and time-dependent effects of various concentrations of fluvastatin on cell viability in B16F10 melanoma cells. Data are presented as the averaged values \pm SE for three independent experiments.

plates. Each sample was tripled and supplied with endogenous control $(\beta$-actin). For tyrosinase expression, the sequence of the forward primer was 5'- GGC CAG CTT TCA GGC AGA GGT -3' and the sequence of the reverse primer was 5'-TGG TGC TTC ATG GGC AAA ATC -3' (Sigma, Genosys, St. Louis MO, USA). Reactions were run in $25 \mu \mathrm{l}$ volume with Power Sybr® Green PCR Master Mix (Applied Biosystems, Warrington, UK), appropriate primer set and $50 \mathrm{ng}$ of cDNA template. Universal thermal conditions, that is $10 \mathrm{~min}$ at $95^{\circ} \mathrm{C}, 40$ cycles of $15 \mathrm{~s}$ at $95^{\circ} \mathrm{C}$ and $1 \mathrm{~min}$ at $60^{\circ} \mathrm{C}$, were used. Data analysis was done with sequence detection software ver. 1.2 (Applied Biosystems, Warrington, UK).

\section{Results and discussion}

UVB irradiation of B16F10 melanoma cell line at 100 $\mathrm{mJ} / \mathrm{cm}^{2}$ daily did not show any important effect on cell viability 24,48 and 72 hours after irradiation procedure, when compared to control non-irradiated cells (Fig. 1).

To determine which fluvastatin concentration shows minimal/no cytotoxic effect, melanoma cells were treated with fluvastatin at various concentrations. Fluvastatin at $0.1 \mu \mathrm{M}$ and $1 \mu \mathrm{M}$ induced relatively low cytotoxic effect during 48 hours, but after 72 hours cell viability was markedly reduced, thus indicating that optimal (maximal, yet not toxic) fluvastatin concentration in medium of the melanoma cell line in further experiments would be $1 \mu \mathrm{M}$ and incubation time should not exceed 48 hours (Fig. 2).

UVB irradiation increased the level of tyrosinase mRNA in B16F10 cells. Surprisingly, in cells treated with $1 \mu \mathrm{M}$ fluvastatin, the level of tyrosinase mRNA was higher when compared to the level resulting from UVB irradiation. Finally, simultaneous irradiation and fluvastatin treatment of $\mathrm{B} 16 \mathrm{~F} 10$ cell line triggered additive effect of tyrosinase mRNA increase, in comparison to stimulation of tyrosinase by UVB (Fig. 3). 


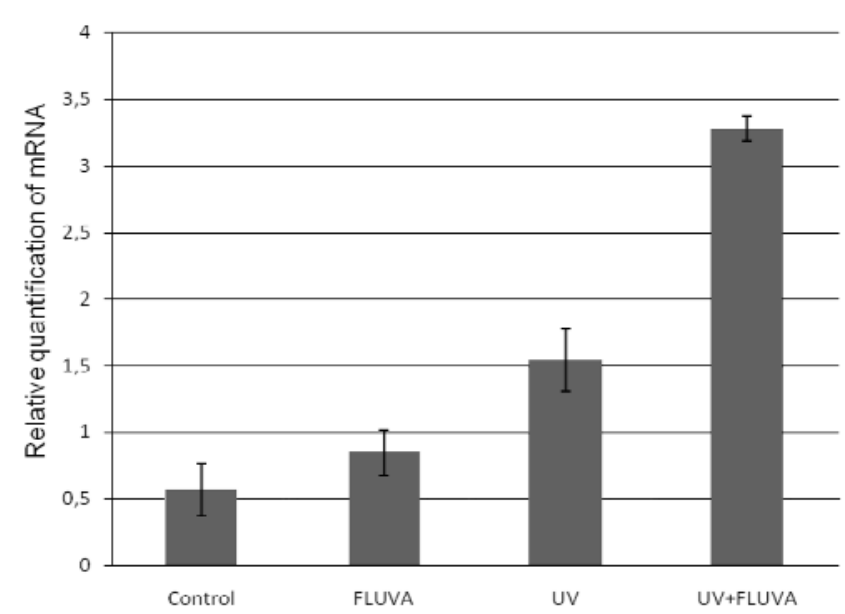

Fig. 3. Effects of UVB irradiation, $1 \mu \mathrm{M}$ fluvastatin (FLUVA) and combination of UVB irradiation/ $1 \mu \mathrm{M}$ fluvastatin (UVB + FLUVA) in B16F10 cell line on the level of tyrosinase mRNA. Relative quantification of mRNA levels from triplicates was averaged \pm SE.

In the current study we show that UVB-induced tyrosinase synthesis of cultured B16F10 melanoma cells is increased by fluvastatin. Levels of tyrosinase mRNA evaluated with use of real time PCR after UVB irradiation of B16F10 melanoma cell line and fluvastatin incubation were increased.

Statins increase expression of bone morphogenetic protein-2 (BMP-2) gene in cells [1] which specifically targets tyrosinase gene expression in primary quail neural crest cultures resulting in increased melanin synthesis [4]. On the other hand, unlike BMP-2 effect in quail melanocytes, BMP-4 stimulates proliferation of melanocytes, down-regulates tyrosinase mRNA and protein levels, decreases melanin content, decreases tyrosinase mRNA stability [13], and purified BMP-4 reduces the number of melanocytes in cultures of avian neural crest cells [14].

Several intracellular signaling pathways have been reported to involve transcriptional activation of tyrosinase gene. Activation of microphthalmia-associated transcription factor (MITF), that regulates tyrosinase gene expression, is known to be a critical event during melanogenesis [15]. Extracellular signal-regulated kinase (ERK) phosphorylates MITF and promotes its degradation, thereby resulting in inhibition of tyrosinase expression and melanogenesis [16]. Further investigations are required to evaluate these proposed signaling pathways.

Since fluvastatin is usually administered orally at daily doses of 20 to $80 \mathrm{mg}$ in patients with hypercholesterolemia, and the plasma concentration typically reaches around $1.0 \mu \mathrm{mol} / \mathrm{L}[17,18]$ our results seem particularly interesting from the clinical point of view. Melanin protects the skin against UV radiation [19]. According to the above results, fluvastatin treatment may potentially increase melanin synthesis and skin protection against UV irradiation.
Acknowledgements: This work was supported by grant 1M15/WB4/07 from Medical University of Warsaw.

\section{References}

[1] Mundy G, Garrett R, Harris S, et al. Stimulation of bone formation in vitro and in rodents by statins. Science. 1999;286:1946-1949.

[ 2] Mundy GR. Statins and their potential for osteoporosis. Bone. 2001;29:495-497.

[ 3] Galus R, Wlodarski PK, Wlodarski KH. Fluvastatin increases heterotopically induced ossicles in mice. Clin Exp Pharmacol Physiol. 2006;33:388-390.

[4] Bilodeau ML, Greulich JD, Hullinger RL, Bertolotto C, Ballotti R, Andrisani OM. BMP-2 stimulates tyrosinase gene expression and melanogenesis in differentiated melanocytes. Pigment Cell Res. 2001;14:328-336.

[5] Sharov AA, Fessing M, Atoyan R, et al. Bone morphogenetic protein (BMP) signaling controls hair pigmentation by means of cross-talk with the melanocortin receptor-1 pathway. Proc Natl Acad Sci U S A. 2005;102:93-98.

[ 6] Glynn SA, O'Sullivan D, Eustace AJ, Clynes M, O'Donovan N. The 3-hydroxy-3-methylglutaryl-coenzyme A reductase inhibitors, simvastatin, lovastatin and mevastatin inhibit proliferation and invasion of melanoma cells. BMC Cancer. 2008;8: 9.

[7] Shellman YG, Ribble D, Miller L, et al. Lovastatin-induced apoptosis in human melanoma cell lines. Melanoma Res. 2005;15: 83-89.

[ 8] Feleszko W, Zagozdzon R, Gołab J, Jakóbisiak M. Potentiated antitumour effects of cisplatin and lovastatin against MmB16 melanoma in mice. Eur J Cancer. 1998;34:406-411.

[9] Feleszko W, Młynarczuk I, Olszewska D, et al. Lovastatin potentiates antitumor activity of doxorubicin in murine melanoma via an apoptosis-dependent mechanism. Int J Cancer. 2002;100:111-118.

[10] Dooley TP, Gadwood RC, Kilgore K, Thomasco LM. Development of an in vitro primary screen for skin depigmentation and antimelanoma agents. Skin Pharmacol. 1994;7:188-200.

[11] Kim DS, Park SH, Kwon SB, Youn SW, Park KC. Effects of lysophosphatidic acid on melanogenesis. Chem Phys Lipids. 2004;127:199-206.

[12] Roméro Ch, Aberdam E, Larnier C, Ortonne JP. Retinoic acid as modulator of UVB-induced melanocyte differentiation. J Cell Sci. 1994;107:1095-1103.

[13] Yaar M, Wu C, Park HY, Panova I, Schutz G, Gilchrest BA. Bone morphogenetic protein-4, a novel modulator of melanogenesis. J Biol Chem. 2006;281:25307-25314.

[14] Jin EJ, Erickson CA, Takada S, Burrus LW. Wnt and BMP signaling govern lineage segregation of melanocytes in the avian embryo. Dev Biol. 2001;233:22-37.

[15] Widlund HR, Fisher DE. Microphthalamia-associated transcription factor: a critical regulator of pigment cell development and survival. Oncogene. 2003;22:3035-3041.

[16] Kim DS, Hwang ES, Lee JE, Kim SY, Kwon SB, Park KC. Sphingosine-1-phosphate decreases melanin synthesis via sustained ERK activation and subsequent MITF degradation. J Cell Sci. 2003;116:1699-1706.

[17] Scripture CD, Pieper JA. Clinical pharmacokinetics of fluvastatin. Clin Pharmacokinet. 2001;40:263-281.

[18] Desager JP, Horsmans Y. Clinical pharmacokinetics of 3-hydroxy-3- methylglutaryl-coenzyme A reductase inhibitors. Clin Pharmacokinet. 1996;31:348-371.

[19] Fernandes SS, Arcuri R, Morgado-Díaz JA, Benchimol M. Increase of melanogenesis by retinoic acid: an ultrastructural and morphometric study. Tissue Cell. 2004;36:95-105. 